\title{
Satisfaction with Quality and Relevance of University Education: Views from Students of Selected Universities in Kenya
}

\author{
Dr. Joseph K. Kirui \\ School of Business and Economics, University of Kabianga
}

\begin{abstract}
University environment has to be conducive if effective learning among the students is to take place. The objective of this study was to investigate the satisfaction level of graduates from public and private universities with the quality and relevance of education they received. The study adopted a triangular survey design where 2272 students from a Public university and 874 students from a Private university formed the population of the study. From these, a sample of 340 and 274 respectively were drawn to take part in the study. Results revealed that the Satisfaction level was higher among Students in public $(\dot{\mathrm{x}}=5.04)$ than in private $(\dot{\mathrm{x}}=4.98)$ though the difference was insignificant with variables under study explaining $39.4 \%$. of the variance. Of the nine dimensions that measured quality of university education, seven were found to significantly explain variations in students' satisfaction while only two were found to be insignificant. Contrary to the usual believe that quality of education services in private universities is higher than in public universities, the findings indicate that the difference is insignificant.
\end{abstract}

Keywords: Satisfaction, Quality, Relevance, University Education, University of Kabianga, Kabarak university DOI: $10.7176 / \mathrm{JMCR} / 54-03$

Publication date:March $31^{\text {st }} 2019$

\subsection{INTRODUCTION}

In higher education, institutions must design their basic goals and objectives to satisfy customers by offering market driven academic and career programs, provide quality teaching and learning environment, and adequate student support services (Ibekwe; 2006, Kaur; 2010). Student's Satisfaction is a relevant measure of quality of university education and many studies have demonstrated that other factors being equal, satisfied individuals are likely to be willing to exert more effort in learning than unsatisfied individuals (Bryant, 2006; Özgüngör, 2010).

Higher education and specifically university education must be of the right quality and appropriate to the needs of the consumers of that education so as to impact on economic and social fabric of the individual and society at large (Nyangau, 2014; Nganga, 2014; Amimo, 2012). To this end, the government of Kenya through various taskforces, commissions and working papers has taken several steps to align the quality of education in general and university education in particular with the needs of the society.

Established in 1964, the Ominde Commission was the pioneer post-independence education reform initiative. This commission was formed out of the realization by the government that infrastructural capacity in the education sector was evidently below par. Also Kenya had emerged from a segregated education system in which schools for non-whites were ill equipped. The commission was tasked with the following terms of reference: 1 survey the existing educational resources of Kenya and 2, and set out an education road map with the objective of establishing an appropriate system of education that would develop the necessary local expertise to replace the departing expatriate personnel (Sifuna, 1992). In the post-colonial period, education was valued as a critical component in developing the human resource required to drive the newly independent nation. The commission recommended: Introduction of a unified education system that would foster national unity and the creation of sufficient human capital for national development; Public participation in construction of schools and expansion of secondary schools funded from public contribution (through 'harambee'). This saw the mushrooming of what was then known as 'Harambee' secondary schools which were often under resourced in terms of trained teachers, modern classrooms and equipped laboratories.

The second effort by the government of Kenya to address the quality and relevance of education was through Sessional Paper No. 10 of 1965 on African Socialism and its Application to Planning in Kenya. This paper was multi-pronged in nature and was aimed at eliminating poverty, disease and ignorance. The third prong, elimination of ignorance and to some extend diseases, was to be achieved through making education available to all. However, successful implementation of these plans and strategies has been hampered by limitations in capacity, financing and governance problems (MoEST, 2014). The emphasis of this paper was provision of primary education to as many children as possible with very little regard being given to quality and relevance.

Between the mid-1960's and early 1970's, the absorption of secondary school and college graduates into civil service and private sector employment was rapid. There was also a concurrent expansion in the number and variety of higher education institutions in Kenya. While this was a welcome development indicator for the newly independent state, its inevitable result was high unemployment once the available job opportunities had been filled. The problem of unemployment was further compounded by an increase in the population of post-secondary school educated youth. It thus became necessary for policy interventions to enhance the employability of youth. 
The Report of the National Committee on Educational Objectives and Policies (The Gachathi Report, 1976), focused on redefining Kenya's educational policies and objectives, giving consideration to national unity, and economic, social and cultural aspirations of the people of Kenya. It resulted in Government support for 'Harambee' schools and also led to establishment of the National Centre for Early Childhood Education (NACECE) at the Kenya Institute of Education (KIE).

In 1981 another expert-driven reform proccess, the Mackay commission, was formed and tasked with examining the feasibility of setting up a second university. The commission recommended the start of Moi University and restructuring and replacement of the 7-4-2-3 system of education with the 8-4-4 model which was designed to be practical oriented. Part of the rationale for the transformative proposals in the Mackay Report was the need to equip Kenyan school leavers with pre-vocational skills and technological education. The 8-4-4 system was therefore designed to make education more relevant to the labour market and to enable the learners to fit more easily in industry. A further innovation of the 8-4-4 system was its emphasis on the capacity of learners to acquire employability skills and also to be entrepreneurs..

Other Recommendations were removal of the advanced (A) level of secondary education, and the expansion of other post-secondary training institutions and establishment of the Commission for Higher Education (CHE) whose mandate was to oversee the planning and coordinating the growth and expansion of university education in Kenya. Its recommendations were fully implemented with the establishment of Moi university and the introduction of 8-4-4 system. However, criticism of the 8-4-4 system began to be voiced by stakeholders in the education sector after 15 years of its implementation. Critics, including parents, argued that the 8-4-4 curriculum was too extensive and its vocational skills component could not effectively empower learners to be self-employed. Also the system has been criticized as responsible for decline in enrolment and retention particularly at the primary and secondary school levels (MoEST, 2004).It was therefore suggested that the system be restructured as a whole or that certain contested components be removed

Another effort by the government to address the question of quality and relevance of education (university) in Kenya was in the legal front. Prior to 1985, each University was established and governed by statutes specific to each university. But the passage of the universities act CAP $210 \mathrm{~B}$ brought the management of universies under a single act. This brought uniformity of quality assurance across universities which hitherto was disjointed.

Before enactment of a unified law, there was no uniformity as far as quality assurance was concerned across universities as each university was responsible for quality assurance of its own academic programs. But since 1985 the universities act CAP 210B Established Commison for higher education (CHE) whose mandate covered quality assurance among other functions in all public and private universities as well as post-secondary institutions. The universities act, No 42 of 2012 provided for the formation of Commission for University Education charged with the responsibility of addressing the need to regulate, coordinate and assure quality in university education as a result of growth and expansion of the university sub sector in Kenya. The Commission was established as a body corporate to make better provisions for the advancement of quality university education in the country.

The Report of the Presidential Working Party on Education and Manpower Training for the Next Decade and Beyond (The Kamunge Report, 1988) focused on improving education financing, quality and relevance. This was at a time when the Government scheme for the provision of instructional materials through the National Textbook Scheme was inefficient and therefore adversely affected the quality of teaching and learning. From the recommendations of the Working Party in 1988, the Government produced Sessional Paper No 6 on Education and Training for the Next Decade and Beyond. This led to the policy of cost sharing between government, parents and communities.

In 1999, The Government formed a commission under the stewardship of Professor Koech. The commission (Koech commission), was tasked with the responsibility of re-examining the 8-4-4 education system in Kenya and make ways and means of enabling the education system to facilitate national unity, mutual social responsibility, accelerated industrial and technological development, life -long learning, and adaptation in response to changing circumstances (Republic of Kenya, 1999). The commission made far reaching recommendations including the removal of vocational subjects, reduced workload for learners, renewed emphasis on acquisition of employability skills over examination outcomes, introduction of Totally Integrated Quality Education and Training (TIQET) approach and the scrapping of 8-4-4 system and reverting to the previous system of 7-4-2-3. However, its recommendations were never implemented because of the cost implication and probably politics because the recommendations went against the view of the government of the day.

All the above initiatives have focused on aligning the education system to suit the needs of the society and individual learners by trying to make learning interesting, meaningful and satisfying to the learner (Bryant, 2006; Özgüngör, 2010)

\subsection{Statement of the problem, Objective and hypothesis of the study}

Service quality is a critical prerequisite for establishing and sustaining satisfying relationship between the customer and service provider. Quality of service in educational institutions is an important factor that is considered for 
attracting, retaining and ensuring effective learning among the students in particular and other stakeholder/customers in general. According to Ministry of Education the number of higher education institutions in Kenya and their intake capacity has increased dramatically since 1970. This rapid increase in the gross enrolment rate has challenged the overall quality of education, particularly in the context of severely limited resources.

The purpose of this study therefore was to investigate whether the trends in the education sector has impacted on the satisfaction level of students thus affecting their capacity to learn.

The objective of this study was to investigate the satisfaction level of graduates from public and private universities with the quality and relevance of education they receive.

Arising from the objective it is hypothesized that:

$\mathrm{H}_{0} 1$ : There is no difference in satisfaction level of graduates from public and private universities with the quality and relevance of education they receive.

\subsection{Literature Review}

Every stakeholder in higher education (e.g. students, government, professional bodies) has its own view of quality due to particular needs (Gruber, Fuß, Voss and Glaeser-Zikuda, 2010). What students do during college counts more in terms of desired outcomes than who they are or even where they go to college (Kuh, 2001). Students are consumers of education services the same way a patient is a consumer of medical services and both of these services have to meet certain thresholds if their consumers are to be satisfied. Student, Just like any other consumer who pay a price to purchase a product or service, pay tuition fees to acquire education and if they are not getting the value for the tuition fee they pay, cognitive dissonance sets in and hence dissatisfaction with the service and the value for money students are looking for is an educational program that will prepare him/her for a successful career and gainful employment (Archambault 2008). Increasingly, higher education institutions are realising that higher education could be regarded as a business-like service industry and they are beginning to focus more on meeting or even exceeding the needs of their students (Gruber, et al, 2010). This they do by focusing on the quality of education they provide to students who are their clients.

It is important to note that education is currently being offered in a fiercly competitive environment (Sim, 2008) and therefore education institutions will have to monitor the quality of the educational services they offer more closely if they are to retain the current and attract new students (Gruber, et al, 2010). Attraction of new students and retention of the current ones is only possible if the educational services offered by any institution satisfies the needs of the students. Student satisfaction in the context of education is described by Elliott and Shin (2002) as the favorability of a student's subjective evaluation of the various outcomes and experiences associated with education. These outcomes and experiences include Student's retention and persistence, student's academic performance as indicated by degree of classification, knowledge, skills and attitudes that ensures employability (Gibbs, 2010)

Several studies exist in literature which attempt to demonstrate various aspects of education that determines its quality from the perspectives of students (Kara, Tanui and Kalai, 2016; Shaltoni, Khraim, Abuhamad and Amer, 2015; Cheruiyot and Maru, 2013 and Uka (2014)

All the foregoing persons in general found out that indicators/ dimensions of quality education that have a bearing on students' satisfaction are academic advising services, career planning services, dean of students services, financial aid services, cafeteria service, social and cultural activities, university orientation program, internet services, testing and grading system, learning materials and environment etc, course content and instruction in the field of study, attitude of the faculty toward the students, variety of courses offered at the university, class size, availability of financial assistance prior to enrolling, accuracy of university information before enrolling, university concern for students as individuals, attitude of university non-teaching staff toward the students, racial harmony at the university, opportunities for student employment, opportunities for personal involvement in campus activities, student government, religious activities and programs, campus media, student journal, newspaper, radio etc. and the university in general.

From the review of both theoretical and empirical literature, a number of issues emerged. Most studies have evaluated quality of education services from the point of view of students from either public or private universities and no study was encountered which attempted to make a simultaneous comparison between the satisfaction level of students in public and private universities with the quality of education.

The weakness with Kara,Tanui and Kalai's (2016) ten dimension- model of educational service quality was that it explained only 41.2 percent of the variations in students' satisfaction in the universities. This was rather low and implies that there are some other variables not captured by their instruments which explain the unexplained 58.8 percent of variance in student's satisfaction with quality of education services, a situation that this study is trying to address by developing a new instrument that incorporates additional dimension suggested by Gibbs (2010). The study by Shaltoni, Khraim, Abuhamad and Amer (2015) though it focused on only one aspect of internet service dimension of quality education, the student portal, it however, did not attempt to bring out the differences in students' satisfaction level with university portals in private and public universities. 
Further no study was encountered in Kenya which has applied triangulation survey approach where views of two or more parties are compared in regards to a single phenomena (in this case quality and relevance of university education) which this study did by comparing the views of graduates from public universities and private

\subsection{METHODOLOGY}

This study adopted a triangular design approach (Rosenberg, Heimler and Morote 2012) where the students satisfaction with quality and relevance of university education was examined from multiple view points i.e. final year students from public and private universities. It targeted a total of 3146 respondents comprising of 2272 final year students from University of Kabianga (Public) and 874 final year student from Kabarak University (Private). From these, a sample of 340 and 274 final year students from University of Kabianga and Kabarak University respectively was selected through random stratification to participate in the study.

A modified instrument named Quality of University Education (UnEdQUAL) questionnaire used. The instrument, a modification of NSSE (2013) questionnaire, incorporates Gibbs (2010) fourteen (14) dimensions of quality education, some aspects of Firdaus' (2006) HEdPERF-SERVPERF questionnaire; Akuegwu and Nwi-ue (2016) Students' Entrepreneurship Culture Development Questionnaire (SECDQ); Cronin and Taylor's (1992) SERVPERF questionnaire; Autio, et al (2001) questionnaire; Fox, Manus and Winder's (2001) short ended study Process Questionnaire; Kara et al (2016) educational service quality and students' satisfaction questionnaire and Kaur \& Bhalla's (2015) questionnaire. Validation on the instrument was done by discussing with experts in the field of education (Firdaus, 2005) while reliability was ascertained through parallel test on similar population. A strong correlation $(\mathrm{r}=0.8, P<0.001)$,was obtained indicating that the aggregate score of the public and private university were strongly correlated an affirmation that both came from a similar population.

\subsection{RESULTS AND DISCUSSION}

\subsection{Response Rates and Missing Value analysis}

From an expected total response rate of 614 students in the final years from both University of Kabianga and Kabarak University, a total of 524 questionnaires were received back representing $85.3 \%$ response rates. From individual universities, $86.8 \%$ and $83.6 \%$ response rates were achieved for University of Kabianga and Kabarak Universities respectively as indicated in Table 4.1.

\section{Table 4.1 Response Rate}

\begin{tabular}{lccc}
\hline University & Expected & Received & Response rates \\
\hline University of Kabianga ( Public ) & 340 & 295 & $86.8 \%$ \\
Kabarak University ( Private) & 274 & 229 & $83.6 \%$ \\
Employers & 86 & 67 & $77.9 \%$ \\
\hline
\end{tabular}

Visual inspection of the 295 questionnaires received from students of university of Kabianga revealed that two questionnaires had more than half of the questions un-responded to and were dropped from analysis. Another Eight questionnaires had more than $5 \%$ missing values and were removed from further analysis. Additional statistical analysis revealed the presence of four outliers leaving 281 questionnaires available for analysis. Out of the 229 questionnaires received from students of Kabarak University, visual inspection revealed that five questionnaires had missing values and were removed from further analysis. Additional preliminary analysis revealed the presence of one outlier leaving 223 valid questionnaires available for further analysis.

Comparing the current response rates with recommendations by Saunders, Lewis, and Thornhills (2009) suggesting a 30-40\% response, Sekaran \& Bougie (2010) advocating for a minimum of 30\%, and Mugenda and Mugenda (2003) recommending response rates of more than $50 \%$ as adequate, $60 \%$ as good and above $70 \%$ rated very good, we therefore find the response rate for this study to be adequate.

\subsection{Descriptive statistics}

To obtain a clear perspective of the rating of individual responses the normality of the data was assessed using Pearsonian Skewness and Kurtosian coefficient. University specific means and standard deviation were analyzed to provide clear description of the responses. Additionally, to establish if there were significant differences in perception of students from public and private universities, a t-test was used. The findings were presented in the following sub sections. 


\begin{tabular}{|c|c|c|c|c|}
\hline & \multirow[t]{2}{*}{ Factor } & \multicolumn{2}{|l|}{ Mean } & \multirow[t]{2}{*}{ t-statistic } \\
\hline & & Public & Private & \\
\hline 1. & Students Staff Ratio & 3.21 & 3.57 & $-4.041 * * *$ \\
\hline 2. & Total study hours & 4.01 & 3.96 & 0.385 \\
\hline 3. & Entrepreneurial Environment & 2.84 & 3.06 & $-2.59 * * *$ \\
\hline 4. & Challenging Curriculum & 3.82 & 3.87 & -0.756 \\
\hline 5. & Depth of Approach to Studying & 2.61 & 2.51 & 1.603 \\
\hline 6. & Student's Engagement & 3.54 & 3.46 & 1.550 \\
\hline 7. & Formative Assessment and Feedback. & 2.90 & 2.86 & 0.492 \\
\hline 8. & Support Services & 2.49 & 2.50 & -.256 \\
\hline 9. & Quality Enhancement Processes. & 3.50 & 3.31 & $2.538 * * *$ \\
\hline 10. & Students Satisfaction Levels & 5.04 & 4.98 & 0.235 \\
\hline
\end{tabular}

\subsubsection{Student-staff ratios}

The ratio of staff to students has been used as a key indicator of quality in higher education across the globe. Shortage of personnel in the Kenyan public universities is well documented and continues to persist despite numerous evidence linking the low academic staffing levels to poor learning outcomes (Cheboi, 2006). Responses on student staff - ratio were as summarized in table 4.3.1

As seen in Table 4.3.1, all the three variables measuring the availability of the teaching staff in supporting students learning were found to exhibit normal distribution. The lecturer student ratio and the level of contact between lecturers and students was found to be significantly higher in private university than in public universities. There was generally neutral or indifferent response among students in both public and private universities on the question of class sizes being kept at minimum to allow for personal attention. Although from the mean scores on the measurement items, the responses from private universities were slightly higher than in public universities, they were not statistically significant. Overally, the student-staff ratio was significantly better in private universities compared to public universities.

From the overall mean of the items measuring student's staff ratio of 3.21 and 3.57 for public and private universities respectively, indications are that conditions are relatively better in private universities as compared to public universities in Kenya

In line with the findings of Gudo, Alel, \& Oanda (2011), lack of or in-adequacy of lecture rooms continues to undermine the levels of interaction between students and lecturers and consequently the quality of teaching in public universities, a position that is better addressed in private universities. A number of events comes into play in a context where mass admissions into university institutions as evident in Kenya. Oversize classes, serious congestion due to limited learning facilities, reliance on part time lecturers who are only available for lecturers, excess workload for permanent lecturers leaving limited time for student consultations and guidance continues to be a cause of worry given the length of time it has taken to be addressed.

\subsubsection{Total study hours}

Effective learning goes beyond the limited hours that that are set out in formal teaching timetables. It is expected that students at a tertiary levels will do more in enhancing their learning out of their own initiatives than at lower learning levels. The time set aside by students for different activities that contribute to entire learning process were distributed as indicated in Table 4.3.2.

Students in public universities were found to spend fewer hours weekly in both lectures (9.8) and co-curricular activities (7) as compared to students in private universities who spent 12 and 7.5 hours respectively. On independent study students in public universities spend more hours (14.2) hours weekly compared to 12.5 hours for their counterparts in private universities. Students at tertiary levels are expected to do more learning on their own than at lower learning levels. Public universities lead in this area.

\subsubsection{Entrepreneurial Environment}

The current inclination of students in public and private universities is towards seeking white collar jobs upon completion of their studies, a trend that a developing economy like Kenya's cannot sustain. In order to reverse this trend, policymakers in University education have championed for the inclusion of entrepreneurial content in the university curriculum and the learning processes.

The levels to which the entrepreneurial culture has been inculcated in the participating universities were as summarized in Table 4.3.3.

Comparatively, students in private universities were more exposed to an entrepreneurial supportive environment than their counterparts in public universities in all the six indicators adopted in the study. Students in private universities were receiving significantly higher number of motivational talks, more exposure to business planning tools and knowledge on sources of venture capital than students in public universities. The integration of entrepreneurship as part of curriculum received the highest rating compared to the other elements used in examining entrepreneurial environment. Overally, based on mean scores of all the various items measuring 
entrepreneurial environment, it is evident that entrepreneurial environment in private universities is relatively better. However, in the two types of universities, existence of entrepreneurship environment is rated average in general.

The existence of functioning entrepreneurship centers was equally evident in both private and public universities. As advocated by Ondigi (2012) learners orientation into entrepreneurship should be aligned into three critical analytical skill areas; understanding knowledge and skills necessary for them to be able to put it into practice and reacting to existing challenges in a manner that props new enterprises. The lower levels of entrepreneurship culture among public universities can be attributed to an inherent culture where, learning is examination oriented and students are more often prepared to pass examinations at the expense of training in skills and competencies centered on solving real life challenges.

\subsubsection{Challenging Curriculum}

University curriculum development in Kenya is based on a flexible approach modeled on the American system (Mautusi 2013, mwebi 2015). It is not standardized and lends individual universities the freedom to develop what is perceived right for the learner varies across and within universities. The results of the assessment of the levels of challenge perceived of their universities curriculum were as indicated in Table 4.3.4.

Students from both public and private universities found elements of their curriculum to exert a relatively higher level of challenge in areas of application, analysis, evaluation and idea formation. Unexpectedly, emphasis on memorizing was significantly higher in private universities compared to public universities, a possible indication of teaching for exams rather than an in-depth understanding of the course content. At test for the differences in mean score reveals that there is no significant difference in the level of challenge in the curricula used in private and public universities.

\subsubsection{Depth of Approach to Studying}

The pioneering work of Marton and Säljö’ (1976) classifies learning approaches into two main types; surface learning where students takes in a collection of discrete units of information that should be memorized in order to answer the anticipated questions and the deep approach recognizing that students will search for underlying concerns, its implications and their meaning before applying the knowledge in solving problems.

As seen in Table 4.3.6., the depth of the study approaches used in both public and private universities was found to be relatively low, in indication of surface learning approach dominance. Developing conclusions based on students own analysis and critical analysis of perspectives presented by other were not significantly different in both public and private universities. However, significant difference was found in the application of numerical information to real world problems with students in public universities rating higher than their counterparts in private universities. The difference between the mean score rating on the depth of studying in private and public universities was not significantly different. There is a strong indication of a dominant surface approach where students in both private and public universities are predominantly treating academic texts, lectures, lecture notes as a mass of data that has to be memorized for recall and reproduction. This is potentially an indicator of surface learning that is closely associated with poor learning outcomes.

\subsubsection{Student's Engagement}

Student's engagement continues to receive recognition as a key element defining learners' levels of satisfaction in higher learning. Student engagement is a powerful driver of quality teaching when it involves dialogue, and not only information on the student's experience (Roseveare \& Henard, 2012)

Evidence from Table 4.3.6.1, point to a common view among students in both private and public universities where the choices of their courses were largely based on future job prospects rather than the intrinsic value derived from their learning. They too similarly detest further study and confine their studies to what is provided by their lecturers, but however at the end, they have derived deep personal satisfaction.

Students in public universities significantly considers University education to be a means to higher paying and secure job, finds learning exiting, relates learning to the real world, will do more work to form their own point of view and will relate new material during their learning to what they already know on the topic than students in private universities. However students in private universities were found to restrict their studies to what is provided and do not find justification in doing extra work. Based on their mean scores, there was no significant difference between private and public universities on the levels of student's engagement.

Viewed for the findings of Crosling, Heagney \& Thomas, (2009), Students learn more when they are actively involved in their education and have opportunities to think about and apply what they are learning in different settings. In recognition that collaborating with others to solve problems or master challenging contents, students will more likely develop valuable skills that prepare them to deal with challenges likely to be encounter in the workplace, the community and their personal lives. Kenya universities will need to put more efforts in creating systems that promotes student engagement more than what is evident from the current study.

A greater proportion of student's engagement arises from their own initiatives in complementing external sources of motivation that promotes engagement. Table 4.3.8 presents a summary of students centered drivers of engagement. 
There was no significant difference on the ability of the students to combine ideas from different courses when completing their assignments in both public and private universities. However students from public universities were able to: link their learning to societal problems and issues, include diverse perspectives in their course discussions (political, religious, ethnic, gender, etc) and sought to understand other's perspectives from their own point of view. Students in private universities on the other hand made more presentations, worked with faculty members on activities other than what relates to their coursework and discussed course related issues with faculty members outside classrooms. Comparing the overall mean score, students from public universities were significantly better in taking their own initiative that students in private universities.

Despite the divergence between the public and private universities on nearly all of the elements examined, their levels of engagement remains relatively low, an indication that student driven initiatives in engaging deeper into their learning is predominantly lacking in Kenyan universities. Parsons and Meyer (1990) in view of this, notes that key elements of quality learning relate to the students' perceptions of quality teaching bearing a strong influence on students approach to study and ultimately learning outcome. A likely call will be for lecturers to change the way in which they teach their courses.

Examining student's engagement based on their experience in applying what they have learnt in the course of the study reveals internships as an area that continues to provide an opportunity for experiencing a workplace environment in both public and private universities in Kenya. Carrying out a research project or a thesis was also equally evident in the two categories of universities. Students in private universities experienced a relatively better engagement with their supervisors than their counterparts in public universities, with low students- lecturer ratio as a likely cause.

With the exception of students self-initiative to summarize what they have been taught after class, students in public universities ranked better than those in private universities in the other indicators of Experience \& Content Based Engagement. These points towards a less motivated and a surface learner who would prefer to rely on the content provided by the lecturer rather than extend their learning beyond basics provided in the classroom.

\subsubsection{Formative Assessment and Feedback.}

The ability to continually reference one's learning to the ultimate learning outcomes is imperative, making assessment and feedback systems an important part of the learning process. The quality of assessment during the entire academic program was as indicated in Table 4.3.7

Formative assessment and provision of feedback in both private and public universities remains low. Instructors in private universities performed better in asking questions at the end of the lesson and provision of detailed and timely feedback on student's academic progress. Inevitably, with lecturers in public universities facing work overload, relatively large class size and inadequate facilities Gudo, et al (2013), provision of quality feedback is more likely to be a key source of the current challenges experienced.

\subsubsection{Support Services}

Holistic learning requires a supportive environment that goes beyond the learner -teacher interaction. An assessment of support services offered by the universities is summarized in Table 4.3.8.

The quality of support services offered in the sampled universities was relatively low. Existence of student support services was better in private universities than in public universities despite most of the differences failing to attain statistical significance. Support for needy students, adequate career counseling services, independent student union, involvement of students in decision making, supporting students in securing internship opportunities, provision of learning support services, redress for student grievances and support for non-academic responsibilities received little emphasis in both private and public universities. Students in public universities received better support when attending off campus activities and events and on study and academic work as compared to private university students. Based on the mean score, there is no significant difference between student support services in private and public universities.

Ilias, Hasan, Rahman and Yasoa (2008); Yeo and Li (2012) in their findings lends a strong empirical support to the existence of strong relationship between students' satisfaction and universities provision of quality students' welfare services.

\subsubsection{Quality Enhancement Processes.}

The presence of structured systems that ensures quality standards are met forms a critical part in University education. The Commission of University Education (CUE) has prescribed minimum standards intended to promote quality learning for universities in Kenya. However, some universities have failed to achieve full compliance (Mukwana et al , 2016).

As seen in Table 4.3.9., there were significant differences on the views of students in public and private universities in four areas indicative of quality enhancement processes put in place by their respective universities. Students in Public universities were significantly more informed of their exams being subjected to external moderation, their institutions being ISO certified and students evaluating their lecturers at the end of every semester compared to their counterparts in private universities. Students in private universities were more aware of CUE visits than those in public universities. The extent to which the universities were responsive towards student's 
grievances was relatively low and with no significant difference between public and private universities. A similar outcome was also evident in regard to the existence of a functioning quality assurance department in the university.

It is notable that most public university students were aware of their universities ISO status but felt strongly that their grievances were not being adequately addressed by the university management, and could be an influential determinant of their overall assessment of their satisfaction with the quality education offered by their respective universities. The current finding concurs with those of Kara et al (2016) who also found a moderate level of satisfaction among students in public universities on quality of administrative services offered.

\subsubsection{1: Students Satisfaction Levels}

The quality of university education is best determined by evaluating its graduates on defined intended outcomes. In this study, the levels of satisfaction with the overall university experience as seen from the eyes of final year graduates was sought. The results from a seven point likert scale rating were as indicated in Table 4.3.11 below.

Despite students in public universities ranking slightly better in their overall rating of their overall levels of satisfaction with their educational experience, it was not significantly different from levels experienced by students in private universities. With $t$ test static $p$ value $<0.05$, the levels of significance set for the study, the null hypothesis holding that there is no difference in satisfaction level of graduates from public and private universities with the quality and relevance of education they receive failed to be rejected. It was therefore concluded that there is no difference in the levels of satisfaction among students in public and private universities in Kenya. The Plausible explanation for similarity in the level of satisfaction of students in public and private universities with their educational experiences is the fact that the same lecturers who teach in public institutions also teach in private institutions on part time basis using the same pedagogical techniques (Abagi et al, 2005).

\subsection{Exploratory Factor Analysis}

The many factors that come into play in any learning environment collectively will determine the satisfaction levels of a learner. In determining the underlying latent elements on which the students assed their satisfaction with university education they received, Principal component analysis (PCA) was employed and is presented in the following subsections.

\subsubsection{Students satisfaction}

In assessing the dimensions of quality and relevance of university education from the student's perspective, we adopted a modified instrument named Quality of University Education (UnEdQUAL), leveraging from diverse quality dimensions constructs used across higher learning institutions across the world. In the final questionnaire nine (9) dimensions of quality and relevance of education namely: Student-staff ratios, total study hours, entrepreneurship environment, , Challenging curriculum, Depth of approach to studying, students engagement, Formative assessment and feedback, Support services, Quality enhancement processes and Output/product were tested.

To ascertain if the initial latent constructs were evident in assessment of Kenyan graduates, PCA was employed. As a prerequisite to factor analysis, sample adequacy and assumption of un-correlated variables were first confirm using Kaiser-Meyer-Olkin Measure of Sampling Adequacy and Bartlett's Test of Sphericity. A summary of the results are indicated in Table 4.4.1

Table 4.4.1 KMO and Bartlett's Test Results

\begin{tabular}{ll}
\hline Test & Results \\
\hline Kaiser-Meyer-Olkin Measure of Sampling Adequacy. & 0.793 \\
Bartlett's Test of Sphericity (Approx. Chi-Square) & $16335.74 * * *$
\end{tabular}

Based on the recommendation of Tabachnick \& Fidell (2007), Kaiser-Meyer-Olkin index of greater than 0.6 is considered adequate. The current KMO index of 0.793 , was an indication that the sample was adequate for factor analysis. Bartlett's test was used to test the levels of correlation between variables assuming a null hypothesis that all variable variances were equal against the alternate hypothesis that they are different. For Factor Analysis to be considered suitable, the Bartlett's Test of Sphericity $p$ values must be less than 0.05 . With the current test $p$ value of 0.000 , the null hypothesis was hence rejected, an indication of low correlation between variable variances.

All the sixty seven questions relating to students satisfaction were factor analyzed using principal component analysis with Varimax (orthogonal) rotation. From the student's satisfaction questionnaire, the analysis yielded Fifteen factors explaining a total of $57.7 \%$ of the variance for the entire set of variables with minimum communalities of $43 \%$, an indication that the variables were strongly related with each other as previously confirmed through Bartlett's Test of Sphericity. Fifteen items in the student's satisfaction and entrepreneurial orientation questionnaire did not load on any of the extracted components and were subsequently removed from further analysis.

Three items measuring lecturer student ratio, levels of contact between lecturers and students and class size loaded on component one (1) explaining $3.53 \%$ of the total variations and was interpreted as a lecturer-students interaction. Among the five items set out to measure the hours that students spent in learning and co curriculum activities, time spent with lecturers did not load on any component, while independent study, preparation for class 
and time spent on co curriculum activities loaded on component two (2) explaining $3.64 \%$ of the total explained variances and was interpreted as study hours. Of the six items set out to measure the entrepreneurship environment present within the university, only three item; encouraging students to pursue business ideas, provision of information on venture capital sources and integration of entrepreneurship in all academic programs loaded on component (3) Explaining $4.449 \%$ of the total variances and was interpreted as entrepreneurship environment. From the initial eight items intended to assess the extent to which the students found their curriculum challenging, seven were found to load on component four (4) explaining $8.39 \% \%$ of the total variances and was interpreted as challenging curriculum, with one item; memorizing course materials failing to load on any component.

Out of the ten items used to assess the depth of approach, all except one; confining studies to what is given in class or within the course outline loading on one component (5) labeled depth of approach explaining $6.554 \%$ of the total variances. From eleven items used to assess the degree to which students were engaged in their studies, four items; combining ideas from different courses when completing assignments, giving course presentation, holding formal leadership position and working with faculty in a research project did not load on any item leaving eight items, explaining $10.08 \%$ of the total variances as significant items loading on component (6) labeled student engagement.

All the seven items intended to measure students' formative assessment and feedback loaded on a single component explaining $7.344 \%$ of the variances and was named formative assessment and feedback. Assessment of support services had ten items but four; support for needy students, provision of career counseling \& advising, support received during time spent during study and support when attending off-campus activities failed to load on any component, with the remaining four items loading on a single component labeled student support services explaining $6.893 \%$ of the total variances. Quality enhancement processes had six items. Only one item student evaluation of their lecturers at the end of every semester did not load on any item, leaving the remaining five item as significant measures explaining $6.821 \%$ of the total variations.

\subsection{Hypothesis Testing}

There is no difference in satisfaction level of graduates from public and private universities with the quality and relevance of education they receive

To test the hypothesis, an independent sample $t$ test was employed. Students rating on their overall satisfaction from their university experience grouped into private and public universities was first subjected to a Levene's Test for Equality of Variances to assess whether equality of means was to be assumed. With resulting Levene's test results $(F=6.29, \mathrm{p}>0.05)$ returning $\mathrm{p}$-values greater that the set significance level of 0.05 , we fail to reject the null hypothesis and conclude that there is insufficient evidence to claim that the variances of students satisfaction scores are not equal.

Table 4.6.1: Independent Sample t -test Results

\begin{tabular}{lccccccc}
\hline \multicolumn{1}{c}{ University } & \multirow{2}{*}{ Mean } & SD & & & \multicolumn{2}{c}{ Sig. } & \multicolumn{2}{c}{ Levene's Test } \\
\cline { 6 - 9 } $\begin{array}{l}\text { Public } \\
\text { Private }\end{array}$ & 5.04 & 1.277 & t Statistic & df & (2-tailed) & F & Sig. \\
\hline
\end{tabular}

With equality of variance assumed, the resulting $t$ - test statistic $(t=0.608, p>0.05)$ with $p$ values greater than the levels of significance set for the study at 0.05 , we fail to reject the null hypothesis and conclude that the levels of students satisfaction with the quality of education offered in public and private universities were not significantly different. Intuitively, this implies that the quality of education offered in public and private universities were not significantly different. This concurs with the findings of Gudo, Olel \& Oanda (2011) citing Shortage of lecturers, inefficient management of university examinations and inadequate funding for research as problems affecting both private and public universities. Naidu \& Derani (2016) found that there were no major differences between the quality of education offered in public and private universities in Malaysia, citing capabilities of lecturers in both public and private universities as of less importance in assessing quality of university education.

The adequacy and robustness of the model in explaining the variances in students satisfaction with their university education was first assessed with the results summarized in Table 4.6.2. and Table 4.6.3.

Table 4.6.2: Variance Explained by University education Quality Dimension Regression Model

R R Square Adjusted R Square $\quad$ Std. Error of the Durbin-Watson

$0.6360 .404 \quad 0.394 \quad 0.850$

Results from the ANOVA test in Table 4.6.2, reveals that the nine independent variables adopted were significantly predictive of student's satisfaction $(\mathrm{F}=37.12, \mathrm{p}<0.05)$ with a combined ability to explaining $39.5 \%$ of the variances in student's experience. The current model explanatory power are close to those reported in Kara et al (2016), ten dimension- model of educational service quality which explained 41.2 percent and relatively 
lower than those reported by Shaltoni, et al (2015). Notwithstanding the fact that the predictors in this study are somewhat different from those of Kara et al (2016) and Shaltoni, et al (2015) and the fact that they variously account for almost the same variance in students' satisfaction with quality of university education, there is need to look for other predictors which will improve the explanatory power of the model

Table 4.6.3: Regression Model ANOVA Test Results

\begin{tabular}{|c|c|c|c|c|c|}
\hline & Sum of Squares & df & Mean Square & $\mathbf{F}$ & Sig. \\
\hline Regression & 241.375 & 9 & 26.819 & 37.121 & $.000^{\mathrm{b}}$ \\
\hline Residual & 355.463 & 492 & .722 & & \\
\hline Total & 596.839 & 501 & & & \\
\hline
\end{tabular}

The contribution of the individual quality dimension in explaining the students satisfaction of final year graduates indicated by the estimated model coefficients were as indicated in Table 4.6.4.

Table 4.6.4: Multiple Linear Regression Model Results Based on Student's satisfaction

\begin{tabular}{lcccccc}
\hline & \multicolumn{2}{c}{ Unsdzd } & Stdzd & & & \\
& B & SE & B & t & Sig. & VIF \\
\hline (Constant) & .265 & .295 & & .899 & .369 & \\
Student Staff ratio & .039 & .014 & .108 & 2.743 & .006 & 1.271 \\
Formative Assessment \& Feedback & .039 & .011 & .152 & 3.527 & .000 & 1.529 \\
Support Services & .022 & .010 & .091 & 2.157 & .031 & 1.461 \\
Entrepreneurship environment & .076 & .016 & .216 & 4.865 & .000 & 1.623 \\
Depth of Approach & .052 & .020 & .100 & 2.616 & .009 & 1.203 \\
Quality Enhancement \& Output & .016 & .011 & .063 & 1.492 & .136 & 1.454 \\
Challenging Curriculum & .028 & .013 & .086 & 2.072 & .039 & 1.423 \\
Students Engagement & .040 & .008 & .192 & 4.830 & .000 & 1.308 \\
Study Hours & .014 & .009 & .058 & 1.629 & .104 & 1.056 \\
\hline
\end{tabular}

Judging from the B values, all the nine dimensions of quality of university education, were found to be positively related to student's satisfaction. However, only two were found to be insignificant while seven were found to significantly explain variations in students' satisfaction. The entrepreneurial environment dimension had the highest $(\beta=0.076)$ positive influence on student's satisfaction indicating that students consider the presence of an entrepreneurial environment as an important component of quality in their university education. Other dimensions in their order of predictive power were: Depth of approach to study $(\beta=0.052)$, students' engagement $(\beta=0.040)$, Student - staff ratio $(\beta=0.039)$, Formative assessment $\&$ feedback $(\beta=0.039)$, Challenging curriculum $(\beta=0.028)$ and students' support services $(\beta=0.022)$.

\subsection{SUMMARY, CONCLUSION \& RECOMENDATION}

\subsection{Summary of Findings}

The first objective of this study was to investigate the satisfaction levels of graduates with the quality and relevance of education offered in both public and private universities in Kenya. The study findings reveal that students were satisfied with the quality of education offered in their universities. A comparison between private and public universities revealed that students in public universities were relatively more satisfied compared to their counterparts in private universities; however the difference was not statistically significant.

There are a number of quality dimensions that were similar in both private and public universities. The number of hours devoted by students to specific learning activities, the levels of challenge in university curriculum, the depth of approach to study, levels of student's engagement, formative assessment and feedback, student's Support Services, student's Entrepreneurial Culture and Students Satisfaction Levels were not significantly different in public and private universities in Kenya. Differences were evident in; student staff ratio, with private universities performing better than public universities; Existence of a supportive entrepreneurial environment was more favorable in private than in public universities, while students in public universities had more opportunities to take self-initiative in their learning than in private universities. Opportunities for seeking practical experience and leadership role were more present in public than in private universities, while quality enhancement processes were more evident in public than in private universities.

In the interest of exploring further on the influence of the quality dimensions on satisfaction of university students, a multiple linear regression model was fitted to the data. Seven out of the nine dimensions of quality and relevance of university education were found to be significant. The existence of a positive entrepreneurship environment was the single most significant determinant of student's satisfaction among university graduates in Kenya. Other factors shaping student's positive experience of university education they received were; depth of approach to study, better student's engagement, presence of an efficient formative assessment and feedback systems, lower student staff ratio and better quality of support services provided by the university. 


\subsection{Conclusions}

Despite evidence showing that students in public universities were relatively more satisfied than students in private universities, the differences in their satisfaction levels is not significant.

The satisfaction levels of final years students form Kenyan universities with the quality of their education is influenced by a number of quality dimensions present within the structure of the learning systems and strictures put in place by the universities. Private universities performed better in maintaining better student- staff ratio and providing a supportive entrepreneurial environment, an indication that private universities were better in providing a conducive system for developing entrepreneurial mindset. While public universities may not have put in place systems to support students in developing their entrepreneur skills, the university environment in itself offers student with better opportunities for self-initiatives, leadership opportunities and self-driven learning whose likely outcomes are self-made entrepreneurs. There a strong indication that the levels of engagement of students in public and private universities are similar. The numbers of hours that they devote to different learning activities, the levels of student's involvement in decision making, the quality of their curriculum, assessment and feedback were similar in both public and private universities. Contrary to the usual believe that quality of education services in private universities is higher than in public universities, the findings indicate that the difference is insignificant.

\subsection{Recommendations}

Evidence from the current findings raises a number of concerns that needs to be addressed; some in the short term while other calls for a long term concerted efforts from different stakeholder in the education sector. With universities in Kenya enjoying relative autonomy in the design of curriculum for courses offered subject to approval by commission for University education, the responsibility of ensuring that the quality and relevance of the courses offered fully meets market needs rest on them. Curriculum design going forwards should be given due attention in an effort to ensure that it captures the industry needs. To ensure continued relevance, continuous monitoring of industry trends and skills requirements should be a central part of university managers and policy makers. The percieved skill mismatch requires a collaborative effort between the industry and universities, and can be best addressed through policies that promote internships for university students, encouraging collaborations in research, transfer of skills between the industry and universities and provision of funding to actualize the policy recommendations.

\subsection{Suggestions for further Research}

Quality and relevance of university education is a relatively wide area, with a plethora of factor coming into play. While the current study may have examined nine dimensions of quality, more that $50 \%$ of the variances in the models used remained unexplained. A further research to explore such unexplained dimensions of quality and relevance will be of great interest.

In the current study, only two universities, one public and one private were selected, a basis on which the current conclusions were derived. Obtaining findings a relatively bigger population will be of interest and a significant improvement to the quality of inferences.

\section{REFFERENCES}

Abagi O., Nzomo J. And Otieno W. (2005) Private higher education in Kenya, International institute for Education Planning

Abdel Monim Shaltoni Hamza Khraim Abdullah Abuhamad Mohammad Amer , (2015)," Exploring students' satisfaction with universities' portals in developing countries A cultural perspective ", The International Journal of Information and Learning Technology, Vol. 32 Iss 2 pp. 82 - 93

Akuegwu B.A, Nwi-ue F.D. (2016), Developing Entrepreneurship Culture among University Students in SouthSouth, Nigeria, Mediterranean Journal of Social Sciences, ISSN 2039-2117, Vol 7 No 2 S1

Akuegwu B.A, Nwi-ue F.D. (2016), Developing Entrepreneurship Culture among University Students in SouthSouth, Nigeria, Mediterranean Journal of Social Sciences , ISSN 2039-2117, Vol 7 No 2 S1

Al-Hilali N, Al-Jaber S, Hussein L (2014) Students' Satisfaction and Achievement and Absorption Capacity in Higher Education, Global Conference on Contemporary Issues in Education, GLOBE-EDU 2014, 12-14 July 2014, Las Vegas, USA

Amimo, C. A. (2012). Tailoring higher education in Kenya to the demands of the postindustrial workplace. Baraton Interdisciplinary Research Journal, 2 (1), 52-58.

Autio E, Keeley R, Klofsten M, G.G.C. Parker ,Hay M(2001) Entrepreneurial Intent among Students in Scandinavia and in the USA, Enterprise and Innovation Management Studies, Vol. 2, No. 2, 2001, 145-160

Bryant, J. L. (2006). Assessing expectations and perceptions of the campus experience: The Noel-Levitz Student Satisfaction Inventory. New Directions for Community Colleges, 134. San Francisco: Jossey-Bass

Cheboi, B (2006, 6th November). Funding Patterns and their Effects on Quality of Higher Education in Kenya. Presented at Kenyatta University. Conference paper. Nairobi. 
Cheruiyot, K T Maru, C.L, (2013)," Service quality and relative performance of public universities in East Africa ", The TQM Journal, Vol. 25 Iss 5 pp. 533 - 546

Crosling, G., Heagney, M. and Thomas, L. (2009) Improving Student Retention in Higher Education: Improving teaching and learning. In Australian Universities' Review, Vol.51, No. 2

Firdaus Abdullah, (2005),"HEDPERF versus SERVPERF", Quality Assurance in Education, Vol. 13 Iss 4 pp.305 $-328$

Fox R, Manus IC, Winder BC (2001) The shortened Study Process Questionnaire: An

Gibbs G. (2010) Dimensions of quality. The higher education academy, ISBN 978-1-907207-24-2

GRUBER, T. et al., 2010. Examining student satisfaction with higher education services: using a new measurement tool. International Journal of Public Sector Management, 23 (2), pp. 105 - 123.

Gudo, C.O., Olel M.A., and Oanda I.O. (2011) 'University Expansion in Kenya and Issues of Quality Education: Challenges and Opportunities', International Journal of Business \& Social Science, 2(20), 203-214.

Ibekwe, L.A. (2006).Using Total Quality Management to achieve Academic Program Effectiveness: An Evaluation of Administrator and faculty Perception in Business Schools at Historically Black Colleges and Universities, Ph.D. Thesis Capella University, Minnesota

Ilias, A., Hasan, H.F.A., Rahman, R.A., \& Yasoa, M.R. (2008). Student Satisfaction and Service Quality: Any Differences in Demographic Factors? International Business Research,1(4). 131-143.

Kara, Tanui, Kalai (2016) Educational Service Quality and Students' Satisfaction in Public Universities in Kenya, International Journal of Education and Social Science, Vol. 3 No. 10; October 2016

Kaur H and Bhalla G S (2015) Satisfaction of Students towards Quality in Higher Education- A Study of Higher Education Sector Punjab (India), Pacific Business Review International Volume 8 issue 6 December

Kaur, D. (2010).Effectiveness of College management- A Comparative View of Teachers and principals AsiaPacific Business Review, 6(2), 150-161

Kuh (2001) The National Survey of Student Engagement: Conceptual Framework and Overview of Psychometric Properties Bloomington, IN: Indiana University Center for Postsecondary Research and Planning

Letcher D W, Neves J S (YEAR) Determinants of undergraduate business student satisfaction, Research in Higher Education Journal,

Marton, F. And Säljö, R. (1976), On Qualitative Differences In Learning: I-Outcome And Process. British Journal of Educational Psychology, 46: 4-11

Mautusi, M., (2013)west Georgia university. Retriueved from west Georgia university, www.evaluation.comn/program

MoEST (2004), a policy framework for education, training And research: Meeting the Challenges of Education, Training and Research in Kenya in the 21 st Century.

MoEST, 2014“Education for All 2015 National Review Report: Kenya"

Mwebi, R. B (2015), Curriculum Design, Implementation and its Effect on Quality Evaluation of Students Learning Outcomes at the University Level in Kenya. International Journal of education and Research Vol. 3 No. 6.

Naidu, P., \& Derani, N. E. S. (2016). A Comparative Study on Quality of Education Received by Students of Private Universities versus Public Universities. Procedia Economics and Finance, 35 , 659-666.

Nyangau, J. Z. (2014). Higher Education as an Instrument of Economic Growth in Kenya. FIRE: Forum for International Research in Education, 1(1). Retrieved from http://preserve.lehigh.edu/fire/vol1/iss1/3

Ondigi, S. R (2012). Role of education in promoting entrepreural skills through classroom practices: teacher training in the Kenyan universities. International Review of Social Sciences and Humanities, Vol. 3, No. 2 , pp. $125-138$

Özgüngör, S. (2010). Identifying Dimensions of students' ratings that best predict students' self efficacy, course value and satisfaction. Eurasian Journal of Educational Research, 38, 146-163.

Parsons, P and Meyer, J.H.F (1990) The academically 'at risk' student: a pilot intervention program and its observed effects on learning outcome, Higher Education 20: 323-334, 1990.

Republic of Kenya (1976) The National Committee on Educational Objectives and Policies (Gathachi Report) Nairobi: Government Printer.

Republic of Kenya (1981) Second University Report of the Presidential Working Party (Mackey Report) Nairobi: Government Printer.

Rosenberg S, Heimler R and Morote, E (2012) Basic Employability Skills: A Triangular Design Approach, Education+Training Vol 54, No. 1, pp.7-20

Roseveare, D. \& Henard, F (2012) Fostering Quality Teaching in Higher Education: Policies and Practices, An IMHE Guide for Higher Education Institutions. Institutional Management in Higher Education.

Saunders, M., Lewis, P. \& Thornhill, A. (2009) Research methods for business students, 5th ed., Harlow, Pearson Education

Sekaran, U., \& Bougie, R. (2010). Research methods for business: A skill building approaches (5th ed.). West 
Sussex,UK: John Wiley \& Sons Ltd.

Sifuna, D. (1992) Development of Education in Africa: The Kenyan Experience.

Sim L. (2008)determinants of students' satisfaction and Students' loyalty in college x: A case study Tabachnick B.G, Fidell L.S. (2007) Using Multivariate Statistics. Boston: Pearson Education Inc.

Yeo, R.K \& Li, J. (2013) "In pursuit of learning: sense-making the quality of work life", European Journal of Training and Development, Vol. 37 Issue: 2, pp.136-160 